\title{
РЕГИОНОВЕДЕНИЕ
}

DOI: http://dx.doi.org/10.15688/jvolsu4.2016.3.12

UDC 947.9(470.6)+002.2(470.6)

Submitted: 28.01 .2016

LBC 63.3(470.6)+76.1(470.6)

Accepted: 09.04.2016

\section{ON THE CENSORSHIP OF KARACHAY NATIONAL BOOK DURING THE PERIOD OF CULTURAL DEVELOPMENT}

\author{
Aminat Kh. Kurmanseitova \\ Karachay-Cherkes Institute for Humanities Research, Cherkessk, Russian Federation
}

\begin{abstract}
In this article on the basis of previously unknown documents, learned by the author from the State archive of the Stavropol region, the State archive of the contemporary history of the Stavropol region, the State archive of Karachay-Cherkess Republic, the branch of the State archive of Karachay-Cherkess Republic "The Centre of documentation of contemporary history", the Central State archive of Republic of Dagestan, the author studies the Institute of censorship in Karachay Autonomous Region during the years of cultural construction. For the first time in the historiography she examines censorship in national book in Karachay regional national Publishing House. The author found that during the formation of the State regional Litho special attention was paid to social origin for censor, as it must have been a member or a candidate for $\operatorname{VKP}(b)$, komsomol and proletarian. The formation of the Institute of political control of books began in the 1930s, however, and at the beginning of the 1940s the State of Karachay Regional national publishing house has not been strengthened. Karachay regional Litho widely used normative documents Glavlit and North Caucasus Regional Litho. Archival documents testify to arrests of authors, compilers and interpreters of educational-methodological and socio-political literature that stood at the origins of the formation of the Karachay books. The holdings of libraries, bookstores and warehouses carried out regular withdrawal of books in the karachay language. On the basis of the analysis of the extensive archival material involved into scientific circulation for the first time, the author comes to the conclusion that the formation of the institution of censorship in Karachay autonomous region, which was started in 1930, continued till 1940. The political control of books and manuscripts was established in the publishing house. The author concludes that Karachay national book was under total control of censors, political editors and reviewers.
\end{abstract}

Key words: Karachay book, Karachay regional Litho, political editor, reviewer, North Caucasus Regional Litho, censorship.

УДК 947.9(470.6)+002.2(470.6)

ББК 63.3(470.6)+76.1(470.6)

Дата поступления статьи: 28.01.2016

Дата принятия статьи: 09.04.2016

\section{К ВОПРОСУ О ЦЕНЗУРЕ НАЦИОНАЛЬНОЙ КНИГИ \\ В КАРАЧАЕВСКОЙ АВТОНОМНОЙ ОБЛАСТИ \\ В ГОДЫ КУЛЬТУРНОГО СТРОИТЕЛЬСТВА (1930-е гг.)}

\section{Аминат Хасановна Курмансеитова}

Карачаево-Черкесский институт гуманитарных исследований, г. Черкесск, Российская Федерация

Аннотация. В первой половине 1930-х гг. Северо-Кавказское краевое лито начало организацию мест-
ных надзорных органов печати в автономных областях Северного Кавказа. Работа по созданию Карачаевско- 


\section{РЕГИОНОВЕДЕНИЕ}

го областного лито вызвала определенные трудности из-за отсутствия кадров из среды карачаевского народа. При формировании штата областного лито особое значение имели социальное происхождение и партийность кандидатуры на должность цензора, так как он обязательно должен был быть членом или кандидатом ВКП(б), комсомольцем и из крестьян. Во второй половине 1930-х гг. было организовано Карачаевское областное лито. В штате издательства обязательно работал политредактор, отвечавший не только за политическое содержание рукописи, но практически негласно контролировавший деятельность руководителя издательства. Формирование института политредакторов в Кароблнациздате происходило медленно, вплоть до 1940 года.

В статье впервые в отечественной историографии автором исследуется цензура национальной книги в Карачаевском областном национальном издательстве. Работа написана на основе ранее неизвестных документов, извлеченных из Государственного архива Ставропольского края, Государственного архива новейшей истории Ставропольского края, Государственного архива Карачаево-Черкесской Республики (ГА КЧР), филиала (ГА КЧР) Центра документации новейшей истории, Государственного архива Республики Дагестан.

Ключевые слова: карачаевская книга, Карачаевское областное лито, политредактор, рецензент, Северо-Кавказское краевое лито, цензура.

Цензура национальной книги карачаевского народа до сих пор не стала предметом специального исследования. Книге народов Карачаево-Черкесии в годы культурного строительства посвящена лишь статья И.Х. Калмыкова «Печать Карачаево-Черкесии за годы Советской власти» $[17$, с. $46-$ 76], однако проблема цензуры карачаевской книги автором не поднималась. В Советском Союзе все местные лито в своей работе руководствовались документами, исходившими из Главлита и Северо-Кавказского краевого лито. В связи с тем, что специфики цензуры национальной книги не было, Карачаевское областное лито использовало директивы, исходившие от центральных и краевых надзорных органов печати.

Архивный фонд Карачаевского областного лито не сохранился. Тем не менее нам удалось извлечь материал из различных фондов: «Государственного архива КЧР» и филиала (ГА КЧР) Центра документации новейшей истории, Государственного архива Ставропольского края. Выявленные разрозненные документы не дают полных сведений о цензуре национальной книги в Карачаевской автономной области. Используя данный материал, мы попытались воссоздать формирование и организацию работы областного лито в Карачаевской автономной области.

В начале 1930-х гг. Северо-Кавказское краевое лито приступило к организации цензуры национальной книги в Северо-Кавказском крае. Из-за отсутствия кадров формирование штата местного лито в Карачаевской автономной области происходило медленно. Подводя итоги деятельности за первое полу- годие 1934 г., А.А. Волгин, начальник СевероКавказского крайлито, сообщил в Главлит: «На днях я добился письма от Крайкома, которое обязывает местные парторганизации обратить внимание на местную цензуру. <...> Несмотря на принятые меры мною, дело остается пока не налаженным» [8, л. 32-32 об.]. Отделу культуры и пропаганды (культпроп) Северо-Кавказского крайкома партии А.А. Волгин писал: «На днях у меня был работник из Карачая, который ведает “в часы досуга" цензурой. Он мне заявил категорически, что отвечать за эту работу не может $<$.. > он сам официально не проведен Начальником Обллита <...> [9, л. 9].

Несмотря на активную работу Отдела культпропа Северо-Кавказского крайкома ВКП(б) и начальника краевого лито А.А. Волгина по организации органов надзора за печатью в горских областях Северного Кавказа, работа областного отдела лито в Карачаевской автономной области не была поставлена на должном уровне. Организация и подбор кадров в Карачаевском областном лито создавали определенные трудности, так как работники должны были иметь «безупречное классовое происхождение - желательно пролетарское» $[1$, с. 50]. Фактически на должность цензора привлекали бывших крестьян, «прошедших обкатку в городской среде». При комплектовании штата местного лито в Карачае кандидатуры утверждались на бюро обкома партии. Особое значение имели социальное происхождение и партийность кандидатуры на эту должность, так как работник цензуры обязательно должен был быть членом или кандидатом ВКП(б), комсомольцем и обязательно из крестьян. 
4 января 1935 г. на бюро Карачаевского обкома ВКП(б) отделу культуры и пропаганды было рекомендовано утвердить начальником областного лито члена партии Якуба Коркмазова. Он являлся внештатным инструктором по печати в Карачаевской области при Отделе печати Крайкома ВКП(б), образование среднее [20, л. 29]. Начальником областного лито и военной цензуры при Карачаевском областном отделе народного образования 25 мая 1935 г. утвержден Д.П. Байкулов, член ВКП(б) с 1926 года. В 1936 г. уполномоченным областного лито по Кароблнациздату в Кисловодске назначен член ВЛКСМ А.И. Джириков.

4 марта 1937 г. Танский писал в УНКВД Северо-Кавказского края Ганиковскому: «Сообщаю, что начальник Карачаевского Обллита т. Байкулов утерял следующие секретные документы: Приказ Главлита № 105, списки №№ $1,2,3, \ldots 2$ списка по педологии и бюллетень № 4» [14, л. 18]. 21 сентября 1937 г. на бюро Карачаевского обкома партии заслушан вопрос: «Об утере тов. Байкуловым Д. директивных материалов и инструкции по работе ОблЛИТО» и принято специальное постановление [13, л. 11]. В документе указаны факты грубейшего нарушения правил хранения секретных документов заведующим Карачаевским областным лито Д.П. Байкуловым, что привело к их утере. Д.П. Байкулов был уволен с работы. Данное решение бюро обкома партии было доложено в крайлито. Отмечено, что необходимо принять к сведению заявление т. Бредис об утере Байкуловым секретной переписки, по которому ведется следствие. Вопрос о партийной ответственности Байкулова предполагали рассмотреть после окончания следствия. Временно обязанность заведующего Карачаевским областным лито была возложена на Алиева.

В 1937 г. штат областного лито Карачаевской автономной области состоял из четырех единиц: начальник - один, первый цензор два, второй цензор - один. 3 октября 1937 г. начальником областного лито утвержден $\mathrm{Ax}$ мат Османович Текеев, член ВКП(б) [24, л. 164], выпускник Коммунистического университета трудящихся Востока, ранее работавший инструктором Карачаевского обкома партии. 28 октября 1937 г. первым цензором Карачаевского областного лито назначен
Юнус Урусов, член ВЛКСМ, выпускник Карачаевского педтехникума, окончивший учительские курсы и курсы газетных работников областных, краевых и центральных газет [26, л. 205]. В это время утверждены: первым цензором Залихат Биболатовна Эркенова - выпускница профтехшколы, вторым цензором - Осман Ахьяевич Хубиев, член ВЛКСМ, выпускник рабфака, окончивший краевые курсы газетных работников. 5 сентября 1938 г. обязанности военного цензора были возложены на начальника Карачаевского областного лито Павла Алексеевича Гончарова, члена ВКП(б), старшего «комполита» запаса [27, л. 118]. В 1941 г. цензором Карачаевского областного лито был утвержден Шамиль Зулкарнаевич Байрамкулов, кандидат в члены ВКП(б), образование среднее, «последнее место работы - служил в Красной Армии» [30, л. 91].

В начале 1930-х гг. в Карачаевской автономной области было начато формирование института политического контроля книг и периодической печати. 18 июля 1933 г. Карачаевским облисполкомом принято специальное постановление «О работе Областного издательства и укреплении кадровых работников по издательству» [3, л. 43 об.]. Заведующим Карачаевским областным издательством утвержден Маджит Халилов, заведующим типографией назначен А.Х. Расулов, должность технического редактора поручена X. Батчаеву. В документе предполагалось согласиться с решением Коллегии областного РКИ по вопросу работников издательства и искажений в их работе. Отмечалось, что в связи с особой ответственностью за перевод и составление стабильных учебников до подыскания кандидатуры постоянного литературного редактора политическое редакторство возложить на Якуба Коркмазова и Абдулкерима Халкечева, освободив их от всей остальной работы на месяц. Политредактором и заместителем заведующего Карнациздатом 1 июля 1940 г. был утвержден Кеккез Мамушевич Коркмазов [29, л. 283].

По общественно-политической литературе и школьным учебникам Кароблнациздата 27 марта 1933 г. утверждены рецензенты: «И. Каракетов, У. Байрамкулов, А. Черенков, 
О. Урусов, Нечесов, Х. Чагиров, М. Кипкеев» $[19$, л. 241].

В 1934 г. газета «Северо-Кавказский большевик» сообщила об издании «Букваря» на карачаево-балкарском языке. 9 июня 1934 г. начальник Главлита Б. Волин в циркуляре под грифом «Не подлежит оглашению» отметил, что карачаево-балкарский букварь переиздавать не следует, так как «требуется коренная переделка их или составление новых» [7, л. 11]. Цензоры приняли соответствующие меры. В отчете Северо-Кавказского краевого лито за четвертый квартал 1934 г. указано о конфискации «Букваря» X. Каракотова на карачаевском языке [10, л. 15]. Данное издание изъято начальником крайлито А.А. Волгиным.

Также бюро Северо-Кавказского крайкома партии постановило, что в переводе на карачаевский язык «Примерного сельскохозяйственного устава сельхозартели» отмечены «неправильности и искажения». В самом названии пропущено выражение «принятый вторым всесоюзным съездом колхозников-ударников и утвержденный Советом Народных Комиссаров СССР и Центральным Комитетом ВКП(б)» [4, л. 7 об.]. В первой фразе первого раздела были опущены слова «села» и «крестьян», в данном переводе имелись и другие ошибки и недостатки. Карачаевскому обкому партии дано задание тщательно проверить весь перевод рукописи и устранить ошибки в новом издании. В итоге книга «Примерный сельскохозяйственный устав сельхозартели» была конфискована цензурой.

20 июня 1936 г. на бюро Северо-Кавказского крайкома партии утверждается издание проекта Конституции СССР на «балкарско-карачаевском языке» - 25 тыс. экз. (в том числе для Карачая - 15 тыс. экз.) [5, л. 41 об.]. Однако перевод проекта Конституции СССР на карачаевский язык, выполненный Аппаевым и Батчаевым, членами бюро обкома партии признан неудовлетворительным. 7 июля 1936 г. бюро обкома ВКП(б) постановило: «Просить Крайком партии об изъятии проекта Конституции, выпущенного Кабардино-Балкарским издательством, как переведенного с политическими искажениями и изобилующими непонятными местами» [22, л. 32]. Членам комиссии Батчаеву, Кипкееву, Шонтаеву и Алиеву поручено перевести проект Конститу- ции на карачаевский язык и представить на бюро обкома партии.

21 августа 1937 г. цензура запретила брошюру М.К. Милых «Вопросы орфографии тюркских языков Северного Кавказа и Дагестана» как содержащую «антисоветщину». В постановлении Карачаевского обкома ВКП(б) указывается, что решение цензуры необходимо довести до сведения Крайкома партии, так как автор М.К. Милых и редактор Г.П. Сердюченко работают в аппарате Краевого комитета Нового Алфавита. Начальнику областного лито А.О. Текееву сделано порицание за проявленную им политическую беспечность «при литировании» данной книги [25, л. 96].

На имя директоров карачаевских областных типографий в г. Кисловодске и г. Микоян-Шахаре в сентябре 1937 г. поступило распоряжение начальника Карачаевского областного лито А.О. Текеева: «КарОблЛИТ ставит Вас в известность, без последующей проверки и визирования с указанием "разрешается" <...> на сигнальном экземпляре, категорически запрещено пускать в свет печатную продукцию, выпускаемых кар[ачаевской] типографией, независимо от характера заказа. В случае обнаружения нарушений данных правил, виновные несут уголовную и материальную ответственность» $[16$, л. 144].

Цензуре подвергалось не только содержание книг, но и их художественное оформление, просматривались иллюстрации, рисунки и фотографии. В циркуляре № 40 от 8 сентября 1934 г. указано: «Предлагаю всем начальникам ОВЦ (отделов военной цензуры. $A$. K.) республик, краев и областей Союза, всем начальникам Крайлитов и Обллитов поставить перед собою, как актуальнейшую задачу, улучшение внешнего качества книги (иллюстрации, расцветка, переплет, печать)» [6, л. 28]. Начальник Северо-Кавказского краевого лито Танский, получив данный циркуляр, специально исследовал художественное оформление национальных книг и сообщил: «В 1934 г. Кароблнациздатом издан Букварь для карачаево-балкарских школ Хамзата Каракотова в редакции Якуба Коркмазова, утвержденный в облоно» $[11$, л. 44]. В документе отмечено, что тематическое содержание «хромает», главным образом по линии нару- 
шения последовательности. Указано, что «на странице 39 даны снимки Ленина и Сталина, а рядом кошки и собаки». Танский писал: «В то же время в букваре имеются снимки школы, герба, СССР, Мавзолея, фабрики и др. $<\ldots>$ Аналогично отношение и к другим снимкам Ленина и Сталина $<\ldots$..> Указанным автором в 1934 г. также издан “Букварь” для ликвидации неграмотности взрослых. В этом букваре аналогичные и безобразные ошибки» [11, л. 44]. Письмо было направлено заведующему отделом культпропа Карачаевского обкома партии, а копии адресованы отделу культпропа Северо-Кавказского крайкома ВКП(б) и начальнику Карачаевского областного лито. Танский требовал, чтобы заведующий Отделом культпропа Карачаевского обкома партии высказал свое мнение об этих учебниках и о своем решении сообщил в краевое лито [11, л. 46-47]. «Букварь» на карачаево-балкарском языке Хамзата Каракотова из-за грубых методических ошибок был изъят из библиотек, школ и книжного склада.

В конце 1930-х гг. в Карачаевской автономной области был сформирован институт цензуры, где национальная книга проходила предварительную и последующую цензуру. Все рукописи рецензировались и проходили политическое редактирование. В своей деятельности Карачаевское областное лито руководствовалось документами, исходившими из Главлита и Северо-Кавказского краевого лито, так как специфика цензуры национальной книги Главлитом не была предусмотрена. Национальная книга Кароблнациздата находилась под жестким контролем советской цензуры, иногда рукописи изымались в ходе предварительной цензуры, нередки случаи конфискации книг в ходе последующей цензуры. Тщательный контроль карачаевской книги негативно отразился на развитии книжного дела карачаевского народа. В то же время следует отметить, что к работе Карачаевского областного лито было много замечаний из Главлита и Северо-Кавказского краевого лито.

\section{СПИСОК ЛИТЕРАТУРЫ}

1. Блюм, А. В. Советская цензура в эпоху тотального террора. 1929-1953 / А. В. Блюм. - СПб. : Академический проспект, 2000. -312 с.
2. Государственный архив Карачаево-Черкесской Республики (ГА КЧР). - Ф. 309. - Оп. 1.Д. 77. Докладная записка в Карачаевский областной КК-РКИ [Контрольная комиссия ВКП(б) и рабоче-крестьянской инспекции] № 09-2211.

3. ГА КЧР. - Ф. Р-307. - Оп. 1. - Д. 89. О работе Областного издательства и укреплении кадровых работников по издательству.

4. Государственный архив новейшей истории Ставропольского края (ГАНИСК). - Ф. 1. - Оп. 1. Д. 57. О переводах сельскохозяйственного устава сельхозартели на лакский, карачаево-балкарский, чечено-ингушский, лезгинский языки.

5. ГАНИСК. -Ф. 1.-Оп. 1. - Д. 100. О переводе и издании проекта Конституции СССР на языки народов Северного Кавказа.

6. Государственный архив Ставропольского края (ГАСК). - Ф. Р-948. - Оп. 1. - Д. 1. Циркуляр Главлита РСФСР.

7. ГАСК. - Ф. Р-948. - Оп. 1. - Д. 2. Начальнику Главлита.

8. ГАСК. - Ф. Р-948. - ОП. 1. - Д. 2. Ответ начальника Северо-Кавказского крайлита А. Волгина в Главлит.

9. ГАСК. - Ф. Р-948. - Оп. 1. - Д. 3. Докладная записка А. Волгина Культпропу Северо-Кавказского крайкома ВКП(б).

10. ГАСК. - Ф. Р-948. - Оп. 1. - Д. 12. Отчет Северо-Кавказского крайлита за четвертый квартал 1934 года.

11. ГАСК. - Ф. Р-948. - Оп. 1. - Д. 15. Управление по делам литературы, издательств и отдела военной цензуры Северо-Кавказского края. 12 августа 1935 года.

12. ГАСК. - Ф. Р-948. - Оп. 1. - Д. 15. Заведующему Культпропа Карачаевского обкома ВКП(б).

13. ГАСК. - Ф. Р-948. - Оп. 4. - Д. 6. Выписка из протокола № 6 заседания бюро Карачаевского областного комитета ВКП(б) от 21 сентября 1937 года.

14. ГАСК. - Ф. Р-948. - Оп. 4. - Д. 6. Докладная в УНКВД Северо-Кавказского края Ганиковскому.

15. ГАСК. - Ф. Р-948. - Оп. 4. - Д. 7. Начальнику Карачаевского обллита Байкулову.

16. ГАСК. - Ф. Р-948. - Оп. 4. - Д. 7. Директорам Кар[ачаевских] типографий.

17. Калмыков, И. Х. Печать Карачаево-Черкесии за годы Советской власти / И. Х. Калмыков // Труды Карачаево-Черкесского НИИ истории, филологии и экономики. - Ставрополь, 1964. Вып. 4. - С. 46-76.

18. Филиал Государственного архива Карачаево-Черкесской Республики «Центр документации новейшей истории» (Филиал ГА КЧР «ЦДНИ»). - Ф. 1. - Оп. 1. - Д. 18. О полит[ическом] просве[щении] О[бластного] о[тдела] н[ародного] о[бразования]. 
19. Филиал ГА КЧР «ЦДНИ». - Ф. П-45. Оп. 1. - Д. 48. О проверке литературы, изданной на карачаевском языке.

20. Филиал ГА КЧР «ЦДНИ».-Ф. П-45. -Оп. 1.Д. 67. О переводе выводов комиссии по чистке партии на карачаевском языке.

21. Филиал ГА КЧР «ЦДНИ». - Ф. П-45. Оп. 1. - Д. 67. О плане изъятия контрреволюционной литературы.

22. Филиал ГА КЧР «ЦДНИ». - Ф. П-45. -Оп. 1.Д. 69. О просмотре текста Конституции СССР.

23. Филиал ГА КЧР «ШДНИ». - Ф. П-45. -Оп. 1.Д. 73. О тематическом плане Карнациздата.

24. Филиал ГА КЧР «ШДНИ».-Ф. П-45. -Оп. 1.Д. 73. О начальнике Обллито.

25. Филиал ГА КЧР «ШДНИ». - Ф. П-45. -Оп. 1.Д. 74. О брошюре Милых.

26. Филиал ГА КЧР «ШДНИ».-Ф. П-45. -Оп. 1.Д. 74. О цензорах.

27. Филиал ГА КЧР «ШДНИ».-Ф. П-45.-Оп. 1.Д. 79. О начальнике отделом военной цензуры при Обл[астном] лито.

28. Филиал ГА КЧР «ШДНИ».- Ф. П-45. -Оп. 1.Д. 89. О реорганизации редакционного аппарата Карнациздательства.

29. Филиал ГА КЧР «ЦДНИ». - Ф. П-45. - Оп. 1.Д. 89. О политредакторе Карнациздательства.

30. Филиал ГА КЧР «ЦДНИ». - Ф. П-45. Оп. 1. - Д. 98. О работе Байрамкулова Ш.З. цензором Обллито.

31. Центральный государственный архив Республики Дагестан. - Ф. П-1.- Оп. 1. - Д. 1862. К культпропам о[бластных] к[омитетов] Дагестанского, Чеченского, Ингушского, Адыгейского, СевероОсетинского, Карачаевского, Кабардино-Балкарского, Черкесского.

\section{REFERENCES}

1. Blyum A.V. Sovetskaya tsenzura v epokhu totalnogo terrora. 1929-1953. [Soviet Censorship During the Era of Total Terror. 1929-1953]. Saint Petersburg, Akademicheskiy prospekt Publ., 2000. 312 p.

2. Gosudarstvennyy arkhiv KarachaevoCherkesskoy Respubliki [The State Archive of Karachay-Cherkess Republic], F. 309, Op. 1, D. 77. A memo in Karachai Regional KK RCTs [Control Commission of the CPSU (b) and Rabkrin] no. 09-2211.

3. Gosudarstvennyy arkhiv KarachaevoCherkesskoy Respubliki [The State Archive of Karachay-Cherkess Republic], F. R-307, Op. 1, D. 89. On the Work of the Regional Publishing House and the Staff Training.

4. Gosudarstvennyy arkhiv noveyshey istorii Stavropolskogo kraya [The State Archive of the
Contemporary History of Stavropol Region], F. 1, Op. 1, D. 57. On Translation of Agricultural Charter of Agro Associations in Lak, Karachay-Balkar, ChechenIngush, Lezgian Languages.

5. Gosudarstvennyy arkhiv noveyshey istorii Stavropolskogo kraya [The State Archive of the Contemporary History of Stavropol Region], F. 1, Op. 1, D. 100. On the Translation and Publication of the Project of the Constitution of the USSR in the Languages of the Peoples of the North Caucasus.

6. Gosudarstvennyy arkhiv Stavropolskogo kraya [The State Archive of Stavropol Region], F. R-948, Op. 1, D. 1. Circular of the Main Publishing Administration.

7. Gosudarstvennyy arkhiv Stavropolskogo kraya [The State Archive of Stavropol Region], F. R-948, Op. 1, D. 2. To the Chief of Main Publishing Administration.

8. Gosudarstvennyy arkhiv Stavropolskogo kraya [The State Archive of Stavropol Region], F. R-948, Op. 1, D. 2. Response of the Head of the North Caucasus Regional Administration of A. Volgin to Main Administraion.

9. Gosudarstvennyy arkhiv Stavropolskogo kraya [The State Archive of Stavropol Region], F. R-948, Op. 1, D. 3. The Memorandum of A. Volgin to the North Caucasus Kultprop of the Regional Committee of the $\operatorname{VKP}(\mathrm{b})$.

10. Gosudarstvennyy arkhiv Stavropolskogo kraya [The State Archive of Stavropol Region], F. R-948, Op. 1, D. 12. The North Kaucasus Regional Administration Report for the Fourth Quarter of 1934.

11. Gosudarstvennyy arkhiv Stavropolskogo kraya [The State Archive of Stavropol Region], F. R-948, Op. 1, D. 15. The Office for Literature and Publishing Department of MilitaryCensorship of the North Kaucasus Region. August 12, 1935.

12. Gosudarstvennyy arkhiv Stavropolskogo kraya [The State Archive of Stavropol Region], F. R-948, Op. 1, D. 15. To the Head of the Culture and Propaganda of the Karachay Regional Committee of the VKP(b).

13. Gosudarstvennyy arkhiv Stavropolskogo kraya [The State Archive of Stavropol Region], F. R-948, Op. 4, D. 6. The Extract From Protocol no. 6. of the Bureau Meeting of the Karachay Regional Committee of the VKP(b) of September 21, 1937.

14. Gosudarstvennyy arkhiv Stavropolskogo kraya [The State Archive of Stavropol Region], F. R-948, Op. 4, D. 6. The Memorandum to the North Caucasus Territory NKVD to Ganikovsky.

15. Gosudarstvennyy arkhiv Stavropolskogo kraya [The StateArchive of Stavropol Region], F. R-948, Op. 4, D. 7. To the Chief of the Karachay Region Litho to Baykulov.

16. Gosudarstvennyy arkhiv Stavropolskogo kraya [The State Archive of Stavropol Region], F. R-948, Op. 4, D. 7. To Directors of Karachay Printing Houses.

17. Kalmykov I.Kh. Pechat Karachaevo-Cherkesii za gody Sovetskoy vlasti [Print of Karachay-Cherkess 
in the Soviet Power]. Trudy Karachaevo-Cherkesskogo nauchno-issledovatelskogo instituta istorii, filologii i ekonomiki [Works of the Karachay-Cherkess Research Institute of History, Philology and Economics]. Stavropol, 1964, iss. 4, pp. 46-76.

18. Filial Gosudarstvennogo arkhiva Karachaevo-Cherkesskoy Respubliki "Tsentr dokumentatsii noveyshey istorii" [The Branch of the State Archive of Karachay-Cherkess Republic "The Center of Documentation of Contemporary History"], F. 1, Op. 1, D. 18. On Political Education of the Regional Department of Public Education.

19. Filial Gosudarstvennogo arkhiva Karachaevo-Cherkesskoy Respubliki "Tsentr dokumentatsii noveyshey istorii" [The Branch of the State Archive of Karachay-Cherkess Republic "The Center of Documentation of Contemporary History"], F. P-45, Op. 1, D. 48. On the Audit of the Literature Published in Karachai Language.

20. Filial Gosudarstvennogo arkhiva Karachaevo-Cherkesskoy Respubliki "Tsentr dokumentatsii noveyshey istorii" [The Branch of the State Archive of Karachay-Cherkess Republic "The Center of Documentation of Contemporary History"], F. P-45, Op. 1, D. 67. On the Translation of the Commission's Findings on Party Cleaning in Karachai Language.

21. Filial Gosudarstvennogo arkhiva Karachaevo-Cherkesskoy Respubliki "Tsentr dokumentatsii noveyshey istorii" [The Branch of the State Archive of Karachay-Cherkess Republic "The Center of Documentation of Contemporary History"], F. P-45, Op. 1, D. 67. On the Plan Counter-Revolutionary Literature Withdrawal.

22. Filial Gosudarstvennogo arkhiva Karachaevo-Cherkesskoy Respubliki "Tsentr dokumentatsii noveyshey istorii" [The Branch of the State Archive of Karachay-Cherkess Republic "The Center of Documentation of Contemporary History"], F. P-45, Op. 1, D. 69. About Review of the Text of the Constitution of the USSR.

23. Filial Gosudarstvennogo arkhiva Karachaevo-Cherkesskoy Respubliki "Tsentr dokumentatsii noveyshey istorii" [The Branch of the State Archive of Karachay-Cherkess Republic "The Center of Documentation of Contemporary History"], F. P-45, Op. 1, D. 73. About Thematic Plan of Karnacizdat.

24. Filial Gosudarstvennogo arkhiva Karachaevo-Cherkesskoy Respubliki "Tsentr dokumentatsii noveyshey istorii" [The Branch of the
State Archive of Karachay-Cherkess Republic "The Center of Documentation of Contemporary History"], F. P-45, Op. 1, D. 73. About the Chief of Regional Literary Department.

25. Filial Gosudarstvennogo arkhiva Karachaevo-Cherkesskoy Respubliki "Tsentr dokumentatsii noveyshey istorii" [The Branch of the State Archive of Karachay-Cherkess Republic "The Center of Documentation of Contemporary History"], F. P-45, Op. 1, D. 74. About the Brochure of "Milye". 26. Filial Gosudarstvennogo arkhiva Karachaevo-Cherkesskoy Respubliki "Tsentr dokumentatsii noveyshey istorii" [The Branch of the State Archive of Karachay-Cherkess Republic "The Center of Documentation of Contemporary History"], F. P-45, Op. 1, D. 74. About Cenzors.

27. Filial Gosudarstvennogo arkhiva Karachaevo-Cherkesskoy Respubliki "Tsentr dokumentatsii noveyshey istorii" "[The Branch of the State Archive of Karachay-Cherkess Republic "The Center of Documentation of Contemporary History"], F. P-45, Op. 1, D. 79. About the Head of the Division of Military Censorship in Regional Literary Department.

28. Filial Gosudarstvennogo arkhiva Karachaevo-Cherkesskoy Respubliki "Tsentr dokumentatsii noveyshey istorii" "[The Branch of the State Archive of Karachay-Cherkess Republic "The Center of Documentation of Contemporary History"], F. P-45, Op. 1, D. 89. On the Reorganization of the Editorial Apparatus of Karnac Publishing House.

29. Filial Gosudarstvennogo arkhiva Karachaevo-Cherkesskoy Respubliki "Tsentr dokumentatsii noveyshey istorii" "[The Branch of the State Archive of Karachay-Cherkess Republic "The Center of Documentation of Contemporary History"], F. P-45, Op. 1, D. 89.

30. Filial Gosudarstvennogo arkhiva Karachaevo-Cherkesskoy Respubliki "Tsentr dokumentatsii noveyshey istorii" "[The Branch of the State Archive of Karachay-Cherkess Republic "The Center of Documentation of Contemporary History"], F. P-45, Op. 1, D. 98. On the Work of S.Z. Bajramkulov the Censor of the Regional Literary Department.

31. Tsentralnyy gosudarstvennyy arkhiv Respubliki Dagestan [The State Archives of the Republic of Daghestan], F. P-1, Op. 1, D. 1862. To Kultprops of the Regional Committees of Dagestan, Chechen, Ingush, Adyghe, North-Ossetian, Karachay, Kabardino-Balkarian, Cherkessian of the Regional Committees of Party. 


\section{Information About the Author}

Aminat Kh. Kurmanseitova, Candidate of Sciences (History), Senior Researcher, Department of Ethnography of Karachay-Cherkess Republic, Karachay-Cherkess Institute for Humanities Research, Gorkogo St., 1a, 369000 Cherkessk, Russian Federation, akseit@yandex.ru.

\section{Информация об авторе}

Аминат Хасановна Курмансеитова, кандидат исторических наук, старший научный сотрудник отдела этнографии КЧР, Карачаево-Черкесский институт гуманитарных исследований, ул. Горького, 1a, 369000 г. Черкесск, Российская Федерация, akseit@yandex.ru. 